\title{
A Multistage Dynamic Emergency Decision-Making Method considering the Satisfaction under Uncertainty Information
}

\author{
Yong Liu (D) \\ Laboratory of Management Simulation, Chongqing Jiaotong University, Chongqing 400074, China \\ Correspondence should be addressed to Yong Liu; liuevery@gmail.com
}

Received 25 February 2021; Revised 24 March 2021; Accepted 29 March 2021; Published 15 April 2021

Academic Editor: Zheng Wang

Copyright (c) 2021 Yong Liu. This is an open access article distributed under the Creative Commons Attribution License, which permits unrestricted use, distribution, and reproduction in any medium, provided the original work is properly cited.

\begin{abstract}
Emergency decision-making (EDM) is of paramount importance, especially when the emergency occurs. The evolution nature of the emergency, such as multistage, uncertainty, dynamic, and information updating, has been playing a key role in the dynamic emergency decision-making process. However, most existing studies ignored the aforementioned nature. Our approach accounts for the dynamics inherent to a real emergency decision-making process and presents a multistage dynamic emergency decisionmaking (MSDEDM) procedure of a dynamic programming model based on decision-makers' psychological reference satisfactory degree. Firstly, interval-valued trapezoidal intuitionistic fuzzy numbers (IVTrIFNs) are used to depict the relevant fuzziness and uncertainty of information. Secondly, by considering the dynamic evolution process of emergency and the decision-makers' psychological reference expectation effect, the principle of MSDEDM approach is presented. Based on the analysis, the dynamic model on the new psychological reference satisfactory parameter formula is presented to obtain the optimal satisfaction and weight of each stage. Then, the value utility function based on the DMs' risk attitude is proposed to obtain the comprehensive value of each emergency alternative for each stage and achieve the ranking results of each stage. Furthermore, a case study involving the transportation emergency decision-making problem demonstrates that the proposed method can achieve selection of the optimal alternatives for each stage, as well as adjustment of the alternatives for neighbouring stages. Finally, the comparative analysis and sensitivity analysis for the results are used to further verify the feasibility and practicability of the proposed method.
\end{abstract}

\section{Introduction}

Emergencies cause heavy casualties and huge economic losses, such as the appearance and spread of COVID-19 in 2019, explosion accident in Tianjin port in 2015, Wenchuan earthquake in 2008, and SARS in 2003. To minimize these losses as far as possible, the effective emergency decision and response measures must be taken immediately. However, due to the complexity and uncertainty of the decision environment as well as the dynamic nature of the events, it is very difficult to effectively determine the measures for response. It is a typical emergency decision-making (EDM) problem, which has always been a hot research topic of modern decision science. The general objective of EDM is to estimate desirable alternatives on the basis of a set of evaluation criteria by decision-makers (DMs), and its major task is to integrally and effectively depict the decisionmaking environment in some representation, assess alternatives on the criteria with a mathematical modeling procedure, and provide the optimal alternative to the emergency response $[1,2]$. How to determine and take the effective emergency decision and response measures immediately when the emergency occurs is very important $[3,4]$.

Over the years, considerable prominent works have been conducted to enrich the fields. Yu and Lai proposed a distance-based multicriteria decision-making method for group emergency decision support [5]. Taking the EDM as a problem of risk analysis, Liu et al. and Wang et al. presented an EDM approach considering the DMs' decision behaviors based on prospect theory $[6,7]$. Wang et al. focused on regret theory, which means that the DMs tend to generate an expected regret for decision based on past experiences and 
established a decision-making method for emergency response of rainstorm disaster [8]. Xu et al. considered DMs' trust relations and preference risks and developed consensus-based EDM approach [9]. For another solution, Ren et al. introduced the concept of decision information quality and firstly developed a thermodynamic method for EDM [10]. Zhang et al. enumerated all possible situations by the dynamic evolution information of emergency and proposed a linear programming selection model to determine the optimal alternative for each situation [11]. Then, Zhang et al. researched another approach to solve the EDM problem based on game theory, where the different situations were regarded as the strategies between emergencies and DMs [12]. With the emerging information technologies, data mining method was introduced to analyse public attribute preferences for emergency risk decision-making [13]. These methods have done great work and will be useful to EDM. However, for the emergency evolution characteristics consisting of multistage, uncertainty, dynamic, and information updating, the abovementioned decision-making method has some limitations in practical application, such as the description of complex and uncertain decision information, the adjustment mechanism of the alternative between two neighbouring stages, the dynamic nature, and decision information updating. With respect to these limitations, the key to solve the EDM problems is to design a multistage dynamic emergency decision-making (MSDEDM) approach, considering not only comprehensively describing and quantifying the decision environment of uncertainty but also dynamically determining the optimal alternative for the response in time.

The assessment information, obtained from the emergency, is the basis for scientific emergency decision-making $[14,15]$. On the one hand, it can reflect the evolution state of the emergency. On the other hand, it can help DMs to judge the events and form the reliable preference assessment. Due to the decision-making environment of variable events, time limitations, and psychological pressure, researchers have found that it is difficult to determine the preference assessment value on the alternative accurately and timely. Furthermore, the processing of their decision is often uncertain and indecisive. In particular, compared with the single-stage decision-making, the complexity and uncertainty of the dynamic emergency decision-making are significantly increased. Therefore, it is necessary to develop more powerful and flexible tools in order to handle these limitations in real-world application. To overcome the issues, fuzzy-based methods aiming at quantifying the individuals' judgment on the alternatives in forms of fuzzy numbers are widely applied in EDM. For example, Li et al. developed an integrated consensus model based on the fuzzy context to solve the EDM problems [16]. Wang et al. and Farhadinia et al. presented an extended hesitant fuzzy decision-making method based on prospect theory and applied it to EDM studies $[17,18]$. Wei developed an operator-based model and procedures to solve decision-making problems, in which the criteria values take the forms of intuitionistic fuzzy numbers (IFNs) and interval-valued IFNs [19]. Liu et al. introduced the concept of trapezoidal intuitionistic fuzzy numbers (TrIFNs) as a special variant of the IFNs and developed a new approach of ratio ranking TrIFNs to solve emergency alternative assessment problems [20]. Wu and Liu studied the multicriteria decision-making problem, in which the given arguments are expressed with IVTrIFNs [21]. It is worth noting that interval-valued trapezoidal intuitionistic fuzzy numbers (IVTrIFNs), introducing interval number from 0 to 1 to portray the DMs' preference assessment degrees, overcome the difficulty that the degrees of membership, nonmembership, and hesitation cannot be described with crisp numbers in reality. Compared with others, IVTrIFNs have more representational parameters, which can not only describe DMs' preference judgment information more comprehensively and exquisitely but also make the preference judgment results closer to the realistic decision-making environment. IVTrIFNs are advantageous and have been applied in other fields with some success [22-25]. However, few articles studied MSDEDM problems where the assessment information can be depicted in forms of IVTrIFNs. This advantage can thus inspire us to introduce IVTrIFNs into MSDEDM problems.

Considering the dynamic nature of the emergency, the decision-making situation is constantly changing, where the DMs should timely adjust the alternative in response to the continuous development of the emergency. With respect to DMs, the most intuitive feedback of these changing is both the decision situation information changing in stages and updating dynamically. Scholars focus on the dynamic nature of both when studying MSDEDM problems. Recently, a few researchers have involved the changing in stages in the EDM problem. For example, Zheng et al. and Ding et al. proposed a dynamic EDM method for alternatives selection of each status, in which the stage of the change was determined by specific development of events $[4,26]$. Cai et al. studied multistage EMD approach, where the stage weights were calculated by relative entropy optimization technology [27]. $\mathrm{Wu}$ et al. showed that a single-stage emergency decisionmaking method is unreasonable for the real application and, on this basis, the changing of the stage weights explored by the GM $(1,1)$ model [28]. In Xu et al.'s work, Markov technology was introduced to describe the evolution state of the emergency [29]. These studies determined the importance of each stage by some assumption and realized the description of the changing in stages. However, such subjective assumption ignored the real impact of the evolution law on the alternative assessing and ranking, such as the control effectivity of the neighbouring stage caused by the alternative response of the previous stage, the evolution of events, and the updating of DMs' psychological expected information.

Due to the dynamical updating of information, scholars often adopt dynamic methods when studying EDM problem. For example, Hao et al. developed a dynamic weight determination method on fuzzy Bayesian network to solve EDM problem, considering the evolving nature of the events [30]. Yan et al. supposed that the results of disaster information evolution had Markov nature and studied the emergency damage assessment problem [14]. Xu considered DMs' psychological preference and the development events, 
initially defined DMs' satisfactory degree of the alternative with TOPSIS (technique for order preference by similarity to ideal solution) and constructed a multiobjective dynamic optimization model based on the distance measure to adjust the alternatives interactively [31]. Gao et al. constructed a dynamic decision-making framework and proposed a reference point approach based on the DMs' expectation level of alternatives for dynamic emergency response decisions [32]. Wang et al. applied prospect theory to EDM, which can depict the dynamic features of events by dynamic reference point method [33]. Although these studies adopted the dynamic methods including the ideal reference point, the psychological expected reference point, and the mechanism of emotion updating and obtained some good results, more subjective assumptions could also lead to the deviation of decision-making results.

To sum up, in view of the emergency evolution characteristics of multistage, uncertainty, dynamic, and information updating, these existing researches still have some limitations in the literature. (a) Researchers have found that it is difficult to depict the emergency of uncertainty and complexity in real applications. There is a gap between the quantification of the assessment environment and reality. The depiction of the EDM environment uncertainty should be closer to the reality. (b) Researchers had significant achievements in EDM approaches of the single stage but ignored the dynamic nature of the emergency evolution. (c) For the dynamic nature, the adjustment mechanism of the alternative between two contiguous stages has not been studied particularly from aspects like information updating.

Thus, the uncertainty of situation, the dynamic nature of events, and the adjustment of alternatives should be involved. Inspired by the studies of $\mathrm{Xu}$ [31] and Gao et al. [32], the study focuses on the context of fuzzy decision-making and develops an interval-valued trapezoidal intuitionistic fuzzy approach to solve the dynamic emergency response. Both weights of criteria and DMs are completely unknown, and the DMs' satisfactory degree and the dynamic nature of emergency are considered. The main contributions of this paper are presented as follows. (a) We propose a novel EDM approach to determine the optimal alternative at stages under IVTrIFNs environment, in which we construct the satisfactory degree index to quantify the DMs' psychological behaviors. (b) We construct an improved satisfaction degree model, not only portraying the dynamic changing of DMs' psychological behaviors but also avoiding more subjective presupposition. (c) Due to the dynamic nature of emergency, we conduct a multistage dynamic mechanism to achieve the adjustment of the alternatives.
The remainder of the paper is organized as follows. Section 2 reviews the related concepts and definitions of IVTrIFNs. In Section 3, we describe the proposed MSDEDM approach based on the psychological reference satisfactory degree and present its procedure. Section 4 provides a case study on the highway emergency response to illustrate the practicality of feasibility of the proposed MSDEDM approach. We also make a comparative analysis and sensitivity analysis for the results in Section 4. Section 5 presents some concluding remarks and future studies.

\section{Preliminaries}

In this section, the basic concepts of IVTrIFNs are briefly reviewed, including definitions, operators, and the method of score functions.

Let $X$ be a fixed set, $A=\left\langle\left([a, b, c, d] ;\left[\mu_{A}^{L}, \mu_{A}^{H}\right]\right.\right.$, $\left.\left.\left[v_{A}^{L}, v_{A}^{H}\right]\right)\right\rangle$ denotes an interval-valued trapezoidal intuitionistic fuzzy number on $X$, and its membership function and nonmembership function are, respectively, defined as $\mu_{A}=\left[\mu_{A}^{L}, \mu_{A}^{H}\right]$ and $v_{A}=\left[v_{A}^{L}, v_{A}^{H}\right]$, where $a, b, c, d \in R$, $0 \leq \mu_{A}, v_{A} \leq 1$, and $\mu_{A}+v_{A} \leq 1$. Ding and Wang gave some operational laws for IVTrIFNs [23, 34].

Definition 1. Let $x_{i}=\left(\left[a_{i}, b_{i}, c_{i}, d_{i}\right] ;\left[\mu_{i}^{L}, \mu_{i}^{H}\right],\left[v_{i}^{L}, v_{i}^{H}\right]\right),(i=$ $1,2, \ldots, n)$ be a collection of IVTrIFNs, and its score function $S\left(x_{i}\right)$ which is used to evaluate the degree of score of $x_{i}$ can be defined as follows:

$$
S\left(x_{i}\right)=\frac{\left(a_{i}+b_{i}+c_{i}+d_{i}\right)}{8}\left(\mu_{i}^{L}+\mu_{i}^{H}-v_{i}^{L}-v_{i}^{H}\right),
$$

where $S\left(x_{i}\right) \in[-1,1]$. Generally, the larger the value of score function $S\left(x_{i}\right)$, the more the degree of score of $x_{i}$. In addition, we can define the expected value $E\left(x_{i}\right)$ of $x_{i}$ as follows [21, 35]:

$$
E\left(x_{i}\right)=\frac{1}{8}\left(a_{i}+b_{i}+c_{i}+d_{i}\right)\left(1+\mu_{i}-v_{i}\right) .
$$

Under the condition $S\left(x_{i}\right)=S\left(x_{j}\right)(i, j=1,2, \ldots, n)$, we can get the following:
(a) If $E\left(x_{i}\right)>E\left(x_{j}\right)$, then $x_{i}>x_{j}$
(b) If $E\left(x_{i}\right)=E\left(x_{j}\right)$, then $x_{i}=x_{j}$
(c) If $E\left(x_{i}\right)<E\left(x_{j}\right)$, then $x_{i}<x_{j}$

Definition 2. Let $x_{i}=\left(\left[a_{i}, b_{i}, c_{i}, d_{i}\right] ;\left[\mu_{i}^{L}, \mu_{i}^{H}\right],\left[v_{i}^{L}, v_{i}^{H}\right]\right),(i=$ $1,2, \ldots, n)$ be a collection of IVTrIFNs and IVTrIFWA operator is a mapping: $f_{\omega}^{x}: \Omega^{n} \longrightarrow \Omega$, if

$$
\operatorname{IVTrIFWA}\left(x_{1}, x_{2}, \ldots, x_{n}\right)=\underset{i=1}{\oplus} w_{i} x_{i}=\left(\left[\begin{array}{c}
\sum_{i=1}^{n} w_{i} a_{i}, \sum_{i=1}^{n} w_{i} b_{i}, \\
\sum_{i=1}^{n} w_{i} c_{i}, \sum_{i=1}^{n} w_{i} d_{i}
\end{array}\right] ; \begin{array}{c}
{\left[1-\prod_{i=1}^{n}\left(1-\mu_{i}^{L}\right)^{w_{i}}, 1-\prod_{i=1}^{n}\left(1-\mu_{i}^{H}\right)^{w_{i}}\right]} \\
{\left[\prod_{i=1}^{n}\left(v_{i}^{L}\right)^{w_{i}}, \prod_{i=1}^{n}\left(v_{i}^{H}\right)^{w_{i}}\right]}
\end{array}\right)
$$


Thus, IVTrIFWA is referred to as interval-valued trapezoidal intuitionistic fuzzy weighted averaging operator of dimension $n$, where $w=\left(w_{1}, w_{2}, \ldots, w_{n}\right)^{T}$ is the weight vector of $x_{i}(i=1,2, \ldots, n)$, with $w_{i} \in[0,1]$ and $\sum_{i=1}^{n} w_{i}=1$.
Definition 3 (see [21]). Let $x_{i}=\left(\left[a_{i}, b_{i}, c_{i}, d_{i}\right] ;\left[\mu_{i}^{L}, \mu_{i}^{H}\right]\right.$, $\left.\left[v_{i}^{L}, v_{i}^{H}\right]\right),(i=1,2, \ldots, n)$ be a collection of IVTrIFNs, for any ordered pair $\langle\alpha, \beta\rangle, \alpha, \beta \in[0,1], 0 \leq \alpha+\beta \leq 1$, and then the $\alpha$ cut set and the $\beta$ cut set can be, respectively, defined as follows:

$$
\begin{aligned}
& x_{i \alpha}=\left[L_{x_{i}}(\alpha), R_{x_{i}}(\alpha)\right]=\left[a_{i}+\frac{\alpha\left(b_{i}-a_{i}\right)}{\mu_{x_{i}}}, d_{i}-\frac{\alpha\left(d_{i}-c_{i}\right)}{\mu_{x_{i}}}\right], \\
& x_{i}^{\beta}=\left[L_{x_{i}}(\beta), R_{x_{i}}(\beta)\right]=\left[\frac{(1-\beta) b_{i}+\left(\beta-v_{x_{i}}\right) a_{i}}{1-v_{x_{i}}}, \frac{(1-\beta) c_{i}+\left(\beta-v_{x_{i}}\right) d_{i}}{1-v_{x_{i}}}\right],
\end{aligned}
$$

where $\mu_{x_{i}}=\left(\mu_{i}^{L}+\mu_{i}^{H} / 2\right) \geq \alpha$ and $v_{x_{i}}=\left(v_{i}^{L}+v_{i}^{H} / 2\right) \leq \beta$. In addition, we can define the expected value of the $\alpha$ cut set and the $\beta$ cut set, respectively:

$$
\begin{aligned}
& E\left(x_{i \alpha}\right)=\int_{0}^{\mu_{x_{i}}}\left[\eta L_{x_{i}}(\alpha)+(1-\eta) R_{x_{i}}(\alpha)\right] \mathrm{d} \alpha=\frac{\mu_{x_{i}}}{2}\left(\eta\left(a_{i}+b_{i}-c_{i}-d_{i}\right)+c_{i}+d_{i}\right), \\
& E\left(x_{i}^{\beta}\right)=\int_{v_{x_{i}}}^{1}\left[\eta L_{x_{i}}(\beta)+(1-\eta) R_{x_{i}}(\beta)\right] \mathrm{d} \beta=\frac{1-v_{x_{i}}}{2}\left(\eta\left(a_{i}+b_{i}-c_{i}-d_{i}\right)+c_{i}+d_{i}\right) .
\end{aligned}
$$

Then the comprehensive risk expected score function $\operatorname{RES}\left(x_{i}\right)$ can be obtained as follows:

$$
\operatorname{RES}\left(x_{i}\right)=\frac{1}{2}\left(\operatorname{EV}\left(x_{i \alpha}\right)+\operatorname{EV}\left(x_{i}^{\beta}\right)\right)=\frac{\eta\left(a_{i}+b_{i}\right)+(1-\eta)\left(c_{i}+d_{i}\right)}{4}\left(1+\frac{\mu_{i}^{L}+\mu_{i}^{H}}{2}-\frac{v_{i}^{L}+v_{i}^{H}}{2}\right),
$$

where $\eta \in[0,1]$ is an indicator of the DMs' risk attitudinal factor; when $\eta$ approaches 1 , the risk attitude is optimistic; adversely, it is pessimistic. Specifically, $\eta=0.5$ indicates that the attitude of DMs is neutral, and equation (6) simplifies to equation (2), which is similar to the expected value $E\left(x_{i}\right)$ of $x_{i}$. Therefore, we can use $\operatorname{RES}\left(x_{i}\right)$ function to convert the interval-valued trapezoidal intuitionistic fuzzy decision information into a representative crisp value and make a sensitivity analysis for the impact of the ranking based on $\eta$, with consideration of the DMs risk attitude.

\section{A Multistage Dynamic Emergency Decision- Making Method}

Emergency activities fully reflect the emergency decisionmaking characteristics of uncertainty, multistage, dynamic, and information updating. When an emergency breaks out, the managers should always strive to effectively control the development of the emergency situation. They make a scientific study and decision on the situation in the first time and dynamically adjust the emergency plan at the necessary stage according to the development trend of the emergency.
Therefore, the key to solve the problem is how to adjust the response plan dynamically according to the stage of the situation. With respect to the characteristics, we propose a novel dynamic method to make emergency decision on their uncertain opinions.

3.1. Problem Definition. In this section, we introduce the investigated emergency response process. When an emergency breaks out, the managers quickly obtain the limited relevant state information through various ways, such as casualties and property losses, traffic conditions, weather and environment, the rescue force, and emergency supplies. Then, they make a rough analysis of the emergency according to the abovementioned information and give the preference degree values of each alternative on the set of the evaluation criteria. Finally, the comprehensive quantification and ranking of each alternative are carried out. In particular, the preference degree values are based on the maximum satisfaction of each decision-maker for the selected emergency alternative performance.

However, such emergency response process ignores the question of multistage dynamic evolution of emergencies, 
which should be involved. For the first stage, the selected emergency alternative is used to respond to the emergency and also plays a role in the control of emergency. Meanwhile, the emergency is also changing. The decision-makers obtain more and more information about the emergency, and the expected satisfaction of the psychological reference of the emergency alternative performance will also change accordingly. For the next stage, the emergency continues to evolve. The decision-makers give new preference degree values of each alternative on the set of the evaluation criteria. After evaluation, if the new satisfaction of the alternative at the moment reaches the last satisfaction of the moment, the emergency plan will not be adjusted; otherwise, the optimal response plan will be selected by recalculation. For the following stages of emergency development, the abovementioned judgment method is used to determine the new response alternative until the emergency is effectively controlled. The multistage dynamic emergency decisionmaking framework is illustrated in Figure 1.

With regard to the basic framework of multiattribute decision-making problem, the relevant variable parameters involved in the multistage dynamic emergency decisionmaking method are presented in Table 1.

\subsection{Dynamic Adjustment Method Based on the Satisfaction Information Updating}

Definition 4 (see [34]). Let $x_{i}=\left(\left[a_{i}, b_{i}, c_{i}, d_{i}\right] ;\left[\mu_{i}^{L}, \mu_{i}^{H}\right]\right.$, $\left.\left[v_{i}^{L}, v_{i}^{H}\right]\right),(i=1,2, \ldots, n)$ be a collection of IVTrIFNs, and the positive and negative ideal points are, respectively, as follows:

$$
\begin{aligned}
x^{+} & =\left(\left[\max a_{i}, \max b_{i}, \max c_{i}, \max d_{i}\right] ;[1,1],[0,0]\right), \\
x^{-} & =\left(\left[\min a_{i}, \min b_{i}, \min c_{i}, \min d_{i}\right] ;[0,0],[1,1]\right) .
\end{aligned}
$$

$\mathrm{Xu}$ defined a decision satisfaction index based on TOPSIS method [31]. It can be defined as

$$
\phi\left(x_{i}\right)=\frac{d\left(x_{i}, x^{-}\right)}{d\left(x_{i}, x^{+}\right)+d\left(x_{i}, x^{-}\right)},
$$

where $d\left(x_{i}, x^{+}\right)$and $d\left(x_{i}, x^{-}\right)$, respectively, indicate the Hamming distances between $x_{i}$ and ideal points. On the basis of equation (8), we introduce decision-maker's risk preference index $\theta$ and construct a satisfaction function, which can be expressed by

$$
\phi\left(x_{i}\right)=\frac{\theta d\left(x_{i}, x^{-}\right)}{\theta d\left(x_{i}, x^{+}\right)+(1-\theta) d\left(x_{i}, x^{-}\right)},
$$

where $\theta \in[0,1]$. If $\theta>0.5$, the decision-maker's risk preference is positive and optimistic. If $\theta<0.5$, the decisionmaker's risk preference is passive and pessimistic. Also, when $\theta=0.5$, it is neutral, and equation (9) can be simplified as equation (8).

Since the satisfaction index has advantages on objectively describing the decision-maker's expected satisfactory degree of psychological reference, it has been widely used in the research of multiattribute decision-making problems. However, in practical decision-making problems, it is difficult to determine the risk preference index of decisionmakers. Previous studies generally assume that decisionmakers' risk appetite is neutral. In order to overcome this shortcoming, we construct a new satisfaction index calculation method.

Definition 5. Let $x_{i}=\left(\left[a_{i}, b_{i}, c_{i}, d_{i}\right] ;\left[\mu_{i}^{L}, \mu_{i}^{H}\right],\left[v_{i}^{L}, v_{i}^{H}\right]\right),(i=$ $1,2, \ldots, n)$ be a collection of IVTrIFNs, let $\bar{x}$ be the weighted average of $x_{i}$, and let $d\left(x_{i}, \bar{x}\right)$ be the Hamming distance between $x_{i}$ and $\bar{x}$. The satisfaction index of $x_{i}$ can be calculated by

$$
\phi\left(x_{i}\right)=\frac{E\left(x_{i}\right)}{1+V\left(x_{i}\right)}=\frac{\sum_{k=1}^{l} w_{i}^{k} E\left(x_{i}^{k}\right)}{1+\sum_{k=1}^{l} w_{i}^{k} d\left(x_{i}^{k}, \bar{x}_{i}\right)},
$$

where $\phi\left(x_{i}\right) \in[0,1]$, and we determine $\bar{x}$ using the IVTrIFWA operator. $E\left(x_{i}\right)$ and $V\left(x_{i}\right)$ are the expected value and the weighted average deviation value, respectively. The higher $E\left(x_{i}\right)$ is, the higher $x_{i}$ is, which means that a more satisfactory degree on the selected alternative can be obtained by DMs. The smaller $V\left(x_{i}\right)$ is, the smaller the difference in preferences is, which shows that a higher consensus degree on the selected alternative can be obtained by DMs, as well as the higher the satisfaction is. Otherwise, the smaller $E\left(x_{i}\right)$, the higher $V\left(x_{i}\right)$ and the lower the satisfaction index. Based on the principle of maximum satisfactory degree, we construct a programming model as follows.

$$
\begin{array}{ll}
\max & \sum_{i=1}^{m} \tau\left(x_{i j}^{p k}\right) \\
& \phi\left(x_{i j}^{p k}\left(w^{p k}\right)\right) \geq \tau\left(x_{i j}^{p k}\right) \\
\text { s.t. } & \sum_{k=1}^{l} w^{p k}=1, \quad 0 \leq w^{p k} \leq 1 \\
& i=1,2, \ldots, m ; \quad j=1,2, \ldots, n ; \\
& k=1,2, \ldots, l ; \quad p=1,2, \ldots, q .
\end{array}
$$

Then, at state $T^{p}$, the maximum satisfaction degree $\tau^{*}\left(x_{i j}^{p k}\right)$ on the selected alternative and the corresponding weight $w^{* p k}=\left(w^{* p 1}, w^{* p^{2}}, \ldots, w^{* p l}\right)$ are calculated by equation (11). We determine the ranking and optimal alternative $A_{i}$.

Apparently, the DMs' psychological reference satisfactory degree on the performance of the selected alternative is not completely fixed and can be influenced by the dynamic development of the events. With the implementation of the selected $A_{i}$, the emergency will be in control. For the coming stage $T^{p+1}$, the DMs obtain new certain information of the emergency and make new decision if necessary. Using $\tau^{*}\left(x_{i j}^{p k}\right)$ as a decision reference, if $\tau^{*}\left(x_{i j}^{(p+1) k}\right) \geq \tau^{*}\left(x_{i j}^{p k}\right)$, then the current emergency alternative $A_{i}$ is not adjusted and continues to be implemented; otherwise, the new satisfactory expectation degree will be recalculated, and the optimal alternative will be dynamically selected until the 


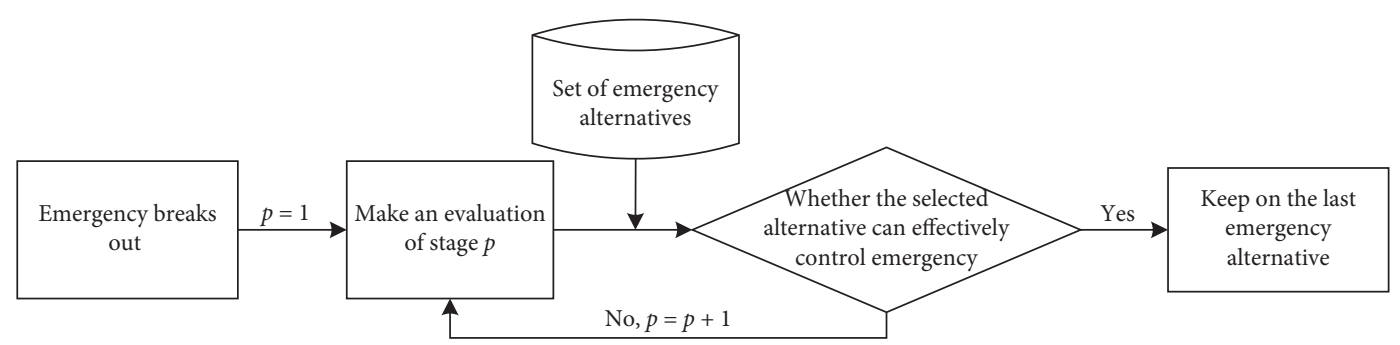

FIGURE 1: Schematic of the multistage dynamic emergency decision-making framework.

TABle 1: Mathematical notations and definitions.

\begin{tabular}{lc}
\hline Symbols & Definitions \\
\hline$T^{p}(p=1,2, \ldots, q)$ & Set of stages in the evolution of an emergency scenario \\
$E^{k}(k=1,2, \ldots, l)$ & Set of experts involved in emergency decision-making \\
$w^{p k}(k=1,2, \ldots, l)$ & Weight of $E^{k}$, with $\sum_{k=1}^{l} w^{p k}=1$ and $0 \leq w^{p k} \leq 1$ \\
$A_{i}(i=1,2, \ldots, m)$ & Set of emergency response alternatives \\
$C_{j}(j=1,2, \ldots, n)$ & Set of evaluation criteria for selection of alternatives \\
$w_{j}^{p k}(k=1,2, \ldots, l)$ & Weight of corresponding criterion, with $\sum_{j=1}^{n} w_{j}^{p k}=1$ and $w_{j}^{p k} \geq 0$ \\
$X^{p k}(p=1,2, \ldots, q ; k=1,2, \ldots, l)$ & Set of preference degree values of each alternative on each criterion by each expert \\
\hline
\end{tabular}

emergency is effectively controlled. Considering the dynamic of the decision-making process, we construct a dynamic programming model as follows.

$$
\begin{array}{ll}
\max & \sum_{i=1}^{m} \tau\left(x_{i j}^{(p+1) k}\right) \\
& \phi\left(x_{i j}^{(p+1) k}\left(w^{(p+1) k}\right)\right) \geq \tau\left(x_{i j}^{(p+1) k}\right) \geq \tau^{*}\left(x_{i j}^{p k}\right) \\
& \\
\text { s.t. } & \sum_{k=1}^{l} w^{(p+1) k}=1,0 \leq w^{(p+1) k} \leq 1 \\
& i=1,2, \ldots, m ; j=1,2, \ldots, n \\
& k=1,2, \ldots, l ; p=1,2, \ldots, q .
\end{array}
$$

3.3. Dynamic Emergency Decision-Making Procedures. In this section, we introduce our proposed approach of the multistage dynamic emergency decision-making. Firstly, the preference degree value of decision-makers is described in the form of interval trapezoidal intuitionistic fuzzy number. On this basis, the entropy weight method is used to calculate the experts' weight in each stage, and the preference degree value on emergency alternative is aggregated to rank and select the optimal alternation. Then, considering the dynamic evolution of the emergency situation, the driving force, which causes the decision-makers to timely adjust emergency response plan, is mainly on whether the stage of emergency plan for emergency performance meets the psychological expected reference satisfaction of decisionmakers. For this aspect, we construct the dynamic decisionmaking model under the influence of decision-makers' psychological reference satisfaction. Also, the experts' weights and the optimal satisfaction of each evolutionary stage are calculated. Finally, the comprehensive value of each emergency decision scheme in each evolutionary stage is calculated to obtain the ranking of alternative decision schemes in each evolutionary stage. According to Gao et al. [32], the detailed procedure is illustrated in Figure 2.

In summary, the steps of the multistage dynamic emergency decision-making method can be detailed as follows:

Step 1. Let the DMs $E^{k}(k=1,2, \ldots, l)$ assess the performance of the emergency alternatives $A_{i}(i=1,2, \ldots, m)$ on the criteria $C_{j}(j=1,2, \ldots, n)$, and determine the normalized preference matrix of each alternative in stage $T^{p}$, which can be expressed by $X^{p k}=\left(x_{i j}^{p k}\right)_{m \times n}, \quad$ where $\quad x_{i j}^{p k}=\left(\left[a_{i j}^{p k}, b_{i j}^{p k}, c_{i j}^{p k}, d_{i j}^{p k}\right] ;[\right.$ $\left.\left.\mu_{i j}^{p k L}, \mu_{i j}^{p k H}\right],\left[v_{i j}^{p k L}, v_{i j}^{p k H}\right]\right), p=1,2, \ldots, q ; k=1,2, \ldots, l$. Step 2. Based on the normalized preference matrix $X^{p k}$, derive the weights $w_{j}^{p k}$ of criteria in stage $T^{p}(p=1,2, \ldots, q)$ by the entropy method [20, 25], which can be calculated by

$$
w_{j}^{p k}=\frac{\left(1-H_{j}^{p k}\right)}{\left(n-\sum_{j=1}^{n}\left[-(\ln m)^{-1} \sum_{i=1}^{m} f_{i j}^{p k} \ln f_{i j}^{p k}\right]\right)} .
$$

where $f_{i j}^{p k}=\left(E\left(x_{i j}^{p k}\right) / \sum_{i=1}^{m} E\left(x_{i j}^{p k}\right)\right)$, and if $f_{i j}=0$, then $f_{i j} \ln f_{i j}=0$.

Step 3. Aggregate the DMs' preference values by IVTrIFWA operator, and calculate the comprehensive preference values on each alternative of each DM at stage $T^{p}$. The comprehensive preference matrix can be expressed by

$$
Y^{p k}=\left(y_{i}^{p k}\right)_{m \times l}=\operatorname{IVTrIFWA}\left(x_{i j}^{p k}\right)=\bigoplus_{j=1}^{n} w_{j}^{p k} x_{i j}^{p k} .
$$

Moreover, calculate the expected matrix of $Y^{p k}$ by equation (2) as follows: 


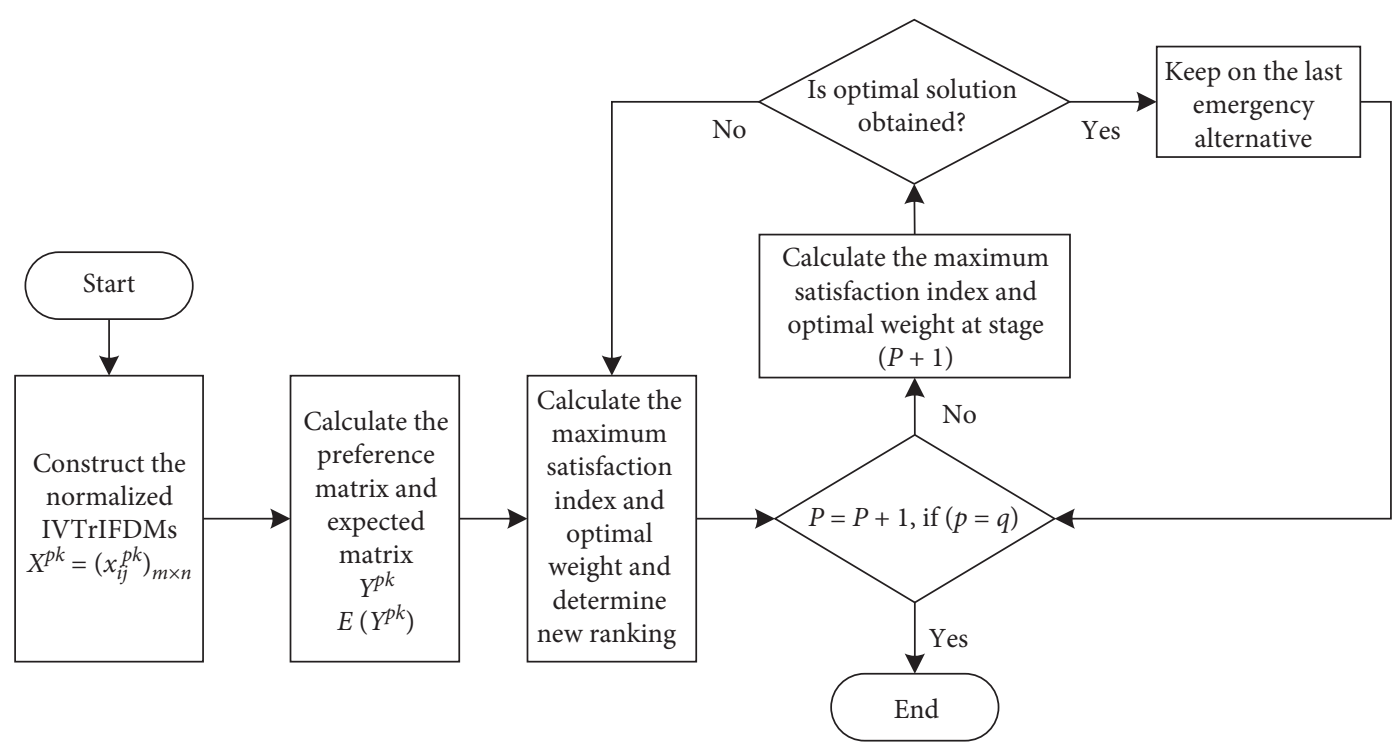

FIgURE 2: Flowchart of the proposed dynamic emergency decision-making methodology.

$E\left(Y^{p k}\right)=\left(E\left(y_{i}^{p k}\right)\right)_{m \times l}, \quad(i=1,2, \ldots, m ; k=1,2, \ldots, l)$.

Step 4. At the current stage $T^{p}$, determine the maximum satisfactory degree $\tau^{*}\left(x_{i j}^{p k}\right)$ on the alternative $A_{i}$ and the corresponding weight $w^{* p k}=\left(w^{* p 1}\right.$, $w^{* p^{2}}, \ldots, w^{* p l}$ ) calculated by equation (11).

Step 5. Obtain the comprehensive preference values $\mathrm{EV}_{i}^{p}$ by IVTrIFWA operator, and determine the ranking of alternatives according to equation (6). Thus, the optimal alternative is $A_{i}^{*}$ at stage $T^{p}$.

Step 6. As the emergency evolves, for the next stage $T^{p+1}$, let the DMs reassess the performance of the emergency alternatives based on the criteria, and determine the new preference matrix of each alternative. Then, calculate the maximum satisfactory degree $\tau^{*}\left(x_{i j}^{(p+1) k}\right)$ on the alternative $A_{i}^{p+1}$ by equation (12). By comparing $\tau^{*}\left(x_{i j}^{(p+1) k}\right)$ and $\tau^{*}\left(x_{i j}^{p k}\right)$, we can get the following:

(a) If $\tau^{*}\left(x_{i j}^{(p+1) k}\right) \geq \tau^{*}\left(x_{i j}^{p k}\right)$, then continue to implement the alternative $A_{i}$, and move to Step 7 .

(b) If $\tau^{*}\left(x_{i j}^{(p+1) k}\right)<\tau^{*}\left(x_{i j}^{p k}\right)$, then move to Step 4 . Recalculate the new satisfactory expectation degree $\tau^{*}\left(x_{i j}^{(p+1) k}\right)$ and the optimal weight $w^{*(p+1) k}=$ $\left(w^{*(p+1) 1}, w^{*(p+1) 2}, \ldots, w^{*(p+1) l}\right)$, and determine the new optimal alternative $A_{i}^{* p+1}$ at stage $T^{p+1}$.

Step 7. When $p=q$, it indicates that the emergency is completely under control; namely, the emergency decision-making process is over.

\section{Illustrative Example}

In this section, the decision-making problem of a transportation emergency is introduced as a case to verify the effectiveness and practicability of the multistage dynamic approach.
4.1. Implementation and Results. A highway section in a mountainous area is experiencing a sudden landslide and mudflow caused by a heavy rainfall. The related highway department is responsible for the emergency alternative decision-making and response. Shortly after the emergency, they firstly organize the relevant experts to study and judge the emergency and quickly launch the emergency alternative. There are our experts $E^{k}(k=1,2,3,4)$ from related professional fields, and three emergency alternatives $A_{i}(i=$ $1,2,3)$ for the event are developed as follows:

$A_{1}$ : do not close lanes, and keep traffic moving in time-phased sharing. Meanwhile, start the rescue work immediately by small machinery and equipment.

$A_{2}$ : close side road, and keep traffic moving in the other lane. Meanwhile, start the rescue work immediately by medium-sized machinery and equipment.

$A_{3}$ : close all lanes, and stop the traffic except emergency vehicles. Meanwhile, start the rescue work immediately by heavy machinery and equipment.

Fully considering the changes in the weather, suppose that there are three different stages of emergency evolution, namely, $T^{p}(p=1,2,3)$. They can be described as follows:

$T^{1}$ : 06:00-10:00 am, it is likely to suffer small-tomoderate rain. Then, with the increasing unstable and uncertain factors, the emergency is also easy to be out of control, and the adverse trends might have a big effect on the rescue progress.

$T^{2}$ : 10:00-14:00 pm, it is likely to suffer moderate-toheavy rain. Then, there is a high probability of worsening the emergency, and the difficulty of managing such emergency is ever increasing.

$T^{3}$ : 14:00-18:00 pm, extreme weather is gradually abating and would benefit the subsequent rescue work. 
For each alternative, five benefit-oriented evaluation criteria $C_{j}(j=1,2,3,4,5)$ are considered by the experts, including the emergency alternative of responsibility, completeness, operability, timeliness, and economy. With the development of emergency, experts need to determine the optimal alternative for the emergency at each stage. Considering the uncertainty of dynamic situation, experts describe the cognitive preferences of each alternative using IVTrIFNs linguistic variables. Table 2 lists the mapping of the IVTrIFNs linguistic variables.

Step 1. Each expert assesses the performance of each alternative on each evaluation criterion, as given in Table 3.

Step 2. Determine the weights $w_{j}^{p k}$ of criteria in stage $T^{p}(p=1,2, \ldots, q)$ by equation (13). Table 4 summarizes the results.

Step 3. The IVTrIFWA operator is used to aggregate the DMs' preference values of stage $T^{p}$ and yield the comprehensive preference values $Y^{p k}$. Then calculate the expected preference value $E\left(Y^{p k}\right)$ and the weighted average deviation value $V\left(Y^{p k}\right)$, as shown in Tables 5 and 6 , respectively.

Step 4. According to stage $T^{p}$, construct a programming model based on equation (11) as follows.

$$
\begin{array}{ll}
\max \sum_{k=1}^{3} \tau\left(x_{i j}^{1 k}\right) & \\
& \frac{0.227 w^{11}+0.492 w^{12}+0.354 w^{13}}{1+0.134 w^{11}+0.158 w^{12}+0.008 w^{13}} \geq \tau\left(x_{i j}^{11}\right) \\
& \frac{0.499 w^{11}+0.521 w^{12}+0.556 w^{13}}{1+0.034 w^{11}+0.006 w^{12}+0.04 w^{13}} \geq \tau\left(x_{i j}^{12}\right) \\
& \frac{0.192 w^{11}+0.202 w^{12}+0.311 w^{13}}{1+0.041 w^{11}+0.031 w^{12}+0.008 w^{13}} \geq \tau\left(x_{i j}^{13}\right) \\
& w^{11}+w^{12}+w^{13}=1 ; w^{13} \geq w^{12} \geq w^{11} \geq 0.3 .
\end{array}
$$

Consequently, according to the model of stage $T^{1}$, we can obtain the most satisfactory degree and the optimal weight as follows: $\tau^{*}\left(x_{i j}^{1 k}\right)=(0.326,0.514,0.237)$ and $w^{* 1 k}=(0.3$, $0.3,0.4)$.

Step 5. Using equation (3), the comprehensive preference values of each alternative $\mathrm{EV}_{i}^{1}$ are calculated as

$\mathrm{EV}_{1}^{1}=([0.447,0.547,0.647,0.747] ;[0.484,0.593],[0.290,0.407])$, $\mathrm{EV}_{2}^{1}=([0.593,0.693,0.793,0.893] ;[0.605,0.710],[0.180,0.290])$, $\mathrm{EV}_{3}^{1}=([0.363,0.463,0.563,0.663] ;[0.368,0.469],[0.429,0.531])$.

Suppose that the experts involved in the assessment have a neutral attitude to face uncertain risk, namely, $\eta=0.5$. Then, using equation (6), the comprehensive risk expected
TABLE 2: Mapping of IVTrIFNs linguistic variables.

\begin{tabular}{lc}
\hline Linguistic terms & \multicolumn{1}{c}{ Linguistic values of TrIFNs } \\
\hline Absolutely low (AL) & $([0.0,0.0,0.1,0.2] ;[0.0,0.0],[1.0,1.0])$ \\
Low (L) & $([0.1,0.2,0.3,0.4] ;[0.1,0.2],[0.7,0.8])$ \\
Fairly low (FL) & $([0.3,0.4,0.5,0.6] ;[0.3,0.4],[0.5,0.6])$ \\
Medium (M) & $([0.4,0.5,0.6,0.7] ;[0.4,0.5],[0.4,0.5])$ \\
Fairly high (FH) & $([0.5,0.6,0.7,0.8] ;[0.5,0.6],[0.3,0.4])$ \\
High (H) & $([0.7,0.8,0.9,1.0] ;[0.7,0.8],[0.1,0.2])$ \\
Absolutely high (AH) & $([0.8,0.9,1.0,1.0] ;[1.0,1.0],[0.0,0.0])$ \\
\hline
\end{tabular}

TABLE 3: Evaluating decision matrix $X^{p k}$ given by expert $E^{k}$ at stage $T^{p}$.

\begin{tabular}{ccccccccccc}
\hline$E^{k}$ & $C_{j}$ & & $T^{1}$ & & & $T^{2}$ & & & $T^{3}$ & \\
& & $A_{1}$ & $A_{2}$ & $A_{3}$ & $A_{1}$ & $A_{2}$ & $A_{3}$ & $A_{1}$ & $A_{2}$ & $A_{3}$ \\
\hline \multirow{4}{*}{$E^{1}$} & $C_{1}$ & M & FH & FL & M & M & H & FH & H & AH \\
& $C_{2}$ & L & FH & FL & FL & FH & AH & H & H & AH \\
& $C_{3}$ & M & FH & FL & M & H & AH & FH & AH & AH \\
& $C_{4}$ & H & H & M & H & H & FH & FH & FH & H \\
& $C_{5}$ & FH & H & FL & H & FH & H & M & FH & H \\
\hline \multirow{4}{*}{$E^{2}$} & $C_{1}$ & FH & H & M & FH & H & H & H & H & AH \\
& $C_{2}$ & H & FH & FL & M & FH & H & FH & FH & H \\
& $C_{3}$ & M & H & FL & H & H & AH & M & FH & H \\
& $C_{4}$ & FH & H & M & M & FH & H & H & H & H \\
& $C_{5}$ & M & FH & FL & FH & H & H & H & AH & H \\
\hline & $C_{1}$ & H & FH & M & H & FH & H & AH & AH & AH \\
& $C_{2}$ & FH & H & FH & FH & H & H & H & H & H \\
$E^{3}$ & $C_{3}$ & FH & H & M & H & FH & H & FH & FH & H \\
& $C_{4}$ & FH & FH & FL & M & H & FH & M & H & AH \\
& $C_{5}$ & L & FH & M & FH & H & M & H & FH & H \\
\hline
\end{tabular}

TABLE 4: Weights $w_{j}^{p k}$ of criteria at stage $T^{p}$.

\begin{tabular}{cccccccccc}
\hline$C_{j}$ & \multicolumn{3}{c}{$T^{1}$} & \multicolumn{3}{c}{$T^{2}$} & & \multicolumn{3}{c}{$T^{3}$} \\
& $E^{1}$ & $E^{2}$ & $E^{3}$ & $E^{1}$ & $E^{2}$ & $E^{3}$ & $E^{1}$ & $E^{2}$ & $E^{3}$ \\
\hline$C_{1}$ & 0.088 & 0.169 & 0.138 & 0.221 & 0.258 & 0.220 & 0.235 & 0.017 & 0.081 \\
$C_{2}$ & 0.460 & 0.460 & 0.421 & 0.429 & 0.255 & 0.088 & 0.047 & 0.269 & 0.046 \\
$C_{3}$ & 0.088 & 0.191 & 0.138 & 0.220 & 0.046 & 0.102 & 0.267 & 0.349 & 0.352 \\
$C_{4}$ & 0.130 & 0.077 & 0.117 & 0.065 & 0.345 & 0.295 & 0.157 & 0.062 & 0.383 \\
$C_{5}$ & 0.234 & 0.103 & 0.186 & 0.065 & 0.096 & 0.295 & 0.294 & 0.303 & 0.138 \\
\hline
\end{tabular}

TABLE 5: Expected preference value $E\left(Y^{p k}\right)$ at stage $T^{p}$.

\begin{tabular}{cccccccccc}
\hline$E^{k}$ & \multicolumn{3}{c}{$T^{1}$} & \multicolumn{1}{c}{$T^{2}$} & & \multicolumn{3}{c}{$T^{3}$} \\
& $A_{1}$ & $A_{2}$ & $A_{3}$ & $A_{1}$ & $A_{2}$ & $A_{3}$ & $A_{1}$ & $A_{2}$ & $A_{3}$ \\
\hline$E^{1}$ & 0.227 & 0.499 & 0.192 & 0.284 & 0.450 & 0.886 & 0.370 & 0.780 & 0.891 \\
$E^{2}$ & 0.492 & 0.521 & 0.202 & 0.334 & 0.510 & 0.853 & 0.463 & 0.749 & 0.851 \\
$E^{3}$ & 0.354 & 0.556 & 0.311 & 0.452 & 0.590 & 0.478 & 0.671 & 0.758 & 0.885 \\
\hline
\end{tabular}

TABle 6: Weighted average deviation value $V\left(Y^{p k}\right)$ at stage $T^{p}$.

\begin{tabular}{cccccccccc}
\hline$E^{k}$ & \multicolumn{3}{c}{$T^{1}$} & \multicolumn{1}{c}{$T^{2}$} & & \multicolumn{3}{c}{$T^{3}$} \\
& $A_{1}$ & $A_{2}$ & $A_{3}$ & $A_{1}$ & $A_{2}$ & $A_{3}$ & $A_{1}$ & $A_{2}$ & $A_{3}$ \\
\hline$E^{1}$ & 0.134 & 0.034 & 0.041 & 0.079 & 0.086 & 0.072 & 0.554 & 0.018 & 0.015 \\
$E^{2}$ & 0.158 & 0.006 & 0.031 & 0.034 & 0.011 & 0.040 & 0.429 & 0.013 & 0.024 \\
$E^{3}$ & 0.008 & 0.040 & 0.080 & 0.117 & 0.094 & 0.561 & 0.007 & 0.007 & 0.009 \\
\hline
\end{tabular}


score $\operatorname{RES}\left(x_{i}\right)$ is obtained as follows: $\operatorname{RES}\left(\operatorname{EV}_{1}^{1}\right)=0.355$, $\operatorname{RES}\left(\mathrm{EV}_{2}^{1}\right)=0.528, \operatorname{RES}\left(\mathrm{EV}_{3}^{1}\right)=0.241$, and $\operatorname{RES}\left(\mathrm{EV}_{2}^{1}\right)>$ $\operatorname{RES}\left(\mathrm{EV}_{1}^{1}\right)>\operatorname{RES}\left(\mathrm{EV}_{3}^{1}\right)$. Thus, at the first stage $T^{1}$, the optimal ranking of the response alternatives is $A_{2}>A_{1}>A_{3}$; namely, the emergency alternative $A_{2}$ can be selected as the most suitable response.

Step 6. In the second stage $T^{2}$, on the basis of the last satisfactory degree $\tau^{*}\left(x_{i j}^{1 k}\right)$, a new programming model based on equation (12) is obtained as follows.

$$
\begin{array}{cl}
\max \sum_{k=1}^{3} \tau\left(x_{i j}^{2 k}\right) & \\
& \frac{0.284 w^{21}+0.334 w^{22}+0.452 w^{23}}{1+0.079 w^{21}+0.034 w^{22}+0.117 w^{23}} \geq \tau\left(x_{i j}^{21}\right) \geq \tau^{*}\left(x_{i j}^{11}\right)=0.326 \\
\text { s.t. } \quad & \frac{0.45 w^{21}+0.51 w^{22}+0.59 w^{23}}{1+0.086 w^{21}+0.011 w^{22}+0.094 w^{23}} \geq \tau\left(x_{i j}^{22}\right) \geq \tau^{*}\left(x_{i j}^{12}\right)=0.514 \\
& \frac{0.886 w^{21}+0.853 w^{22}+0.478 w^{23}}{1+0.072 w^{21}+0.04 w^{22}+0.561 w^{23}} \geq \tau\left(x_{i j}^{23}\right) \geq \tau^{*}\left(x_{i j}^{13}\right)=0.237 \\
& w^{21}+w^{22}+w^{23}=1 ; w^{23} \geq w^{22} \geq w^{21} \geq 0.3 .
\end{array}
$$

Clearly, the above model is unsolvable under the current constraints, which indicates that the previous stage is no longer suitable for managing the current emergency. The current emergency alternative needs to be reassessed and adjusted; meanwhile, the new satisfactory expectation degree can be updated. Consequently, according to equation (11), a new programming model is obtained as follows.

$$
\begin{array}{ll}
\max & \sum_{k=1}^{3} \tau\left(x_{i j}^{2 k}\right) \\
& \frac{0.284 w^{21}+0.334 w^{22}+0.452 w^{23}}{1+0.079 w^{21}+0.034 w^{22}+0.117 w^{23}} \geq \tau\left(x_{i j}^{21}\right) \\
\text { s.t. } \quad & \frac{0.45 w^{21}+0.51 w^{22}+0.59 w^{23}}{1+0.086 w^{21}+0.011 w^{22}+0.094 w^{23}} \geq \tau\left(x_{i j}^{22}\right) \\
& \frac{0.886 w^{21}+0.853 w^{22}+0.478 w^{23}}{1+0.072 w^{21}+0.04 w^{22}+0.561 w^{23}} \geq \tau\left(x_{i j}^{23}\right) \\
& w^{21}+w^{22}+w^{23}=1 ; w^{23} \geq w^{22} \geq w^{21} \geq 0.3 .
\end{array}
$$

Through solving the model, the most satisfactory degree is $\tau^{*}\left(x_{i j}^{2 k}\right)=(0.331,0.486,0.604)$, and the optimal weight is $w^{* 2 k}=(0.333,0.333,0.334)$, respectively. By equation (3), the comprehensive preference values of each alternative $\mathrm{EV}_{i}^{2}$ are obtained as follows:

$$
\begin{aligned}
& \mathrm{EV}_{1}^{2}=([0.460,0.560,0.660,0.760] ;[0.477,0.583],[0.306,0.417]), \\
& \mathrm{EV}_{2}^{2}=([0.583,0.683,0.783,0.883] ;[0.598,0.703],[0.186,0.297]), \\
& \mathrm{EV}_{3}^{2}=([0.670,0.770,0.870,0.946] ;[1.000,1.000],[0.000,0.000]) .
\end{aligned}
$$

Similarly, let $\eta=0.5$, and determine the comprehensive risk expected score $\operatorname{RES}\left(\mathrm{EV}_{i}^{2}\right)$ as follows: $\operatorname{RES}\left(\mathrm{EV}_{1}^{2}\right)=0.356$, $\operatorname{RES}\left(\mathrm{EV}_{2}^{2}\right)=0.517, \quad \operatorname{RES}\left(\mathrm{EV}_{3}^{2}\right)=0.814$, and $\operatorname{RES}\left(\mathrm{EV}_{3}^{2}\right)$ $>\operatorname{RES}\left(\mathrm{EV}_{2}^{2}\right)>\operatorname{RES}\left(\mathrm{EV}_{1}^{2}\right)$. Thus, the optimal ranking of the response alternatives is $A_{3}>A_{2}>A_{1}$, which indicates that the emergency alternative $A_{3}$ is the best for the emergency response at present.

Step 7. For the coming stage $T^{3}$, a new programming model is constructed using equation (12) as follows.

$$
\begin{array}{ll}
\max \sum_{k=1}^{3} \tau\left(x_{i j}^{3 k}\right) & \\
& \frac{0.37 w^{31}+0.463 w^{32}+0.671 w^{33}}{1+0.554 w^{31}+0.429 w^{32}+0.007 w^{33}} \geq \tau\left(x_{i j}^{31}\right) \geq \tau^{*}\left(x_{i j}^{21}\right)=0.331 \\
& \frac{0.78 w^{31}+0.749 w^{32}+0.758 w^{33}}{1+0.018 w^{31}+0.013 w^{32}+0.007 w^{33}} \geq \tau\left(x_{i j}^{32}\right) \geq \tau^{*}\left(x_{i j}^{22}\right)=0.486 \\
& \frac{0.891 w^{31}+0.851 w^{32}+0.885 w^{33}}{1+0.015 w^{31}+0.024 w^{32}+0.009 w^{33}} \geq \tau\left(x_{i j}^{33}\right) \geq \tau^{*}\left(x_{i j}^{23}\right)=0.604 \\
& w^{31}+w^{32}+w^{33}=1 ; w^{33} \geq w^{32} \geq w^{31} \geq 0.3 .
\end{array}
$$

Obviously, the model has an optimal solution, which is obtained as follows: $w^{* 3 k}=(0.3,0.3,0.4)$ and $\tau^{*}\left(x_{i j}^{3 k}\right)=(0.399,0.753,0.863)$. The results show that the previous alternative has played a good role in managing the emergency and should continue to be implemented, namely, $A_{3}>A_{2}>A_{1}$. Meanwhile, the comprehensive risk expected score $\operatorname{RES}\left(\mathrm{EV}_{i}^{3}\right)$ is calculated as follows: $\operatorname{RES}\left(\mathrm{EV}_{1}^{3}\right)=0.665$, $\operatorname{RES}\left(\mathrm{EV}_{2}^{3}\right)=0.762, \operatorname{RES}\left(\mathrm{EV}_{3}^{3}\right)=0.877$, and $\operatorname{RES}\left(\mathrm{EV}_{3}^{3}\right)>$ $\operatorname{RES}\left(\mathrm{EV}_{2}^{3}\right)>\operatorname{RES}\left(\mathrm{EV}_{1}^{3}\right)$, which indicates the effectiveness and reliability of the model at stage $T^{3}$.

In conclusion, for the multistage dynamic emergency decision-making problem, the ranking order of the three stages is $A_{2} \Rightarrow A_{3} \Rightarrow A_{3}$.

4.2. Results Analysis and Discussion. From the abovementioned example, we can see that the severe weather not only is the key emergency instigator but also affects the emergency response procedure, and thus the weather changes should be involved in the dynamic assessment of the alternative. The three alternatives $A_{i}(i=1,2,3)$, showing a progressive nature for emergency response, have different 


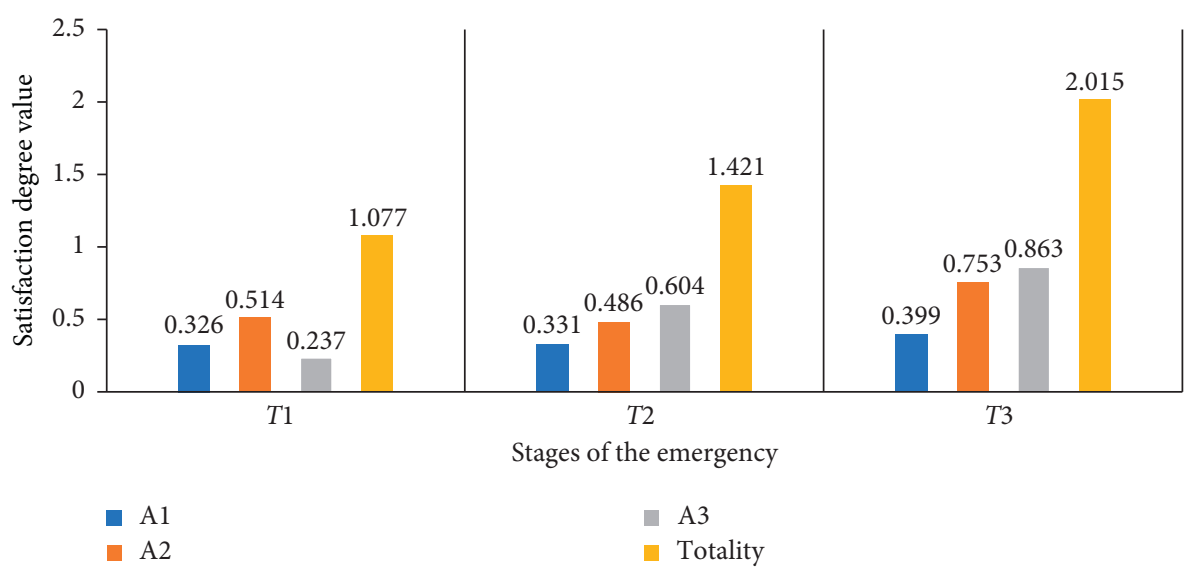

FIGURE 3: Satisfaction degree value of each alternative at each stage.

focus according to the development of the event. It is reasonable for the experts to evaluate the emergency and make multistage decisions to select optimal alternative with respect to the developments. The optimal alternative of each stage can be obtained using the proposed method of dynamic multistage emergency decision-making, and the results are shown in Figures 3 and 4.

Figure 3 presents the satisfactory degree value of each alternative at each stage, showing the preference information updating of the DMs. Obviously, with the emergency development and the selected alternative implementation, the satisfactory degree index of each expert is increasing and getting close to one until the events are effectively controlled. It is indicated from the results, obtained by using the proposed dynamic method based on the satisfactory degree index, that the dynamic emergency decision-making processing involving the changes of DMs' psychological reference on the uncertainties is also reasonable.

Figure 4 shows the comprehensive value of each alternative and the optimal alternative ranking at each stage determined using the proposed dynamic approach. In the first state $T^{1}$, the traffic emergency occurs. Although there is limited and uncertain information for the experts from the events, they still evaluate the situation and select the optimal alternative $A_{2}$. For the implementation of response $A_{2}$, the emergency is evolving according to the internal and external factors and continues to change. For the coming stage $T^{2}$, more explicit information obtained through the various information channels can influence the expectation of the experts' psychological reference satisfaction degree to be continually updated. Then, the decision-making results show that $A_{2}$ is unable to control the emergency effectively, and the alternative is adjusted to $A_{3}$. Next, it happened to stage $T^{3}$, and the new satisfactory degree of $A_{3}$ reaches an acceptable level, namely, $A_{3}$ plays a role in responding to the current emergency. There is no need to adjust alternative $A_{3}$ at this stage. Therefore, on account of the multistage, uncertainty, dynamic, and information updating in reality, it is practical that the emergency decision-making involves the updating process of the DMs' psychological reference satisfaction and the dynamic adjustment mechanism of the emergency response.
In addition, to further verify the stability of the proposed MSDEDM method, we conduct the sensitivity analysis of the DMs' risk attitudinal factor $\eta \in[0,1]$. Table 7 shows the results of the comprehensive risk expected score function $\operatorname{RES}\left(x_{i}\right)$, indicating the influence on the choice of the emergency alternatives. For the variable $\eta \in[0,1]$, we obtain the variation features of $\operatorname{RES}\left(x_{i}\right)$ at each stage, as shown in Figures 5 to 7 .

Depending on the kinds of figures, we can determine that the risk expected score function $\operatorname{RES}\left(x_{i}\right)$ decreases with the increase in value of $\eta$. However, as the risk attitudinal variable increases from 0 to 1 , the obtained alternative rankings at each stage are changed. The ranking of the first stage $T^{1}$ is $A_{2}>A_{1}>A_{3}$, and thus alternative $A_{2}$ is always the optimal one and is selected as the response. For the second stage $T^{2}$, the alternative ranking is $A_{3}>A_{2}>A_{1}$, and $A_{2}$ is adjusted to $A_{3}$. According to the coming stage $T^{3}$, after calculation by the proposed model, the obtained ranking is $A_{3}>A_{2}>A_{1}$, and alternative $A_{3}$ is always the optimal one and is selected as the response similar to the last stage $T^{2}$. Thus, the sensitivity analysis shows that the alternative assessment value can change as the risk attitudinal variable $\eta$ changes at each stage, which should be involved in the decision-making problems. Meanwhile, although the comprehensive value of each alternative is remarkably correlated linearly with the DMs' risk attitudinal factor, the ranking results are not affected by the factor, which further indicates the strong stability of the proposed approach.

Therefore, considering the emergency situations of the multistage, uncertainty, dynamic, and information updating in reality, the proposed MSDEDM approach has the following application advantages: (a) The study introduced IVTrIFNs that have more parameters than others into the multistage dynamic emergency decision-making process, to develop a novel approach for exquisitely describing the heterogeneous preference assessment information of the experts with respect to the uncertainty. This means that the obtained assessment information by IVTrIFNs can be closer to reality and let the results be more accurate in the situations of fuzziness and uncertainty. It is especially well suited for the dynamic emergency decision-making with the characteristics of uncertain information, time limitations, 


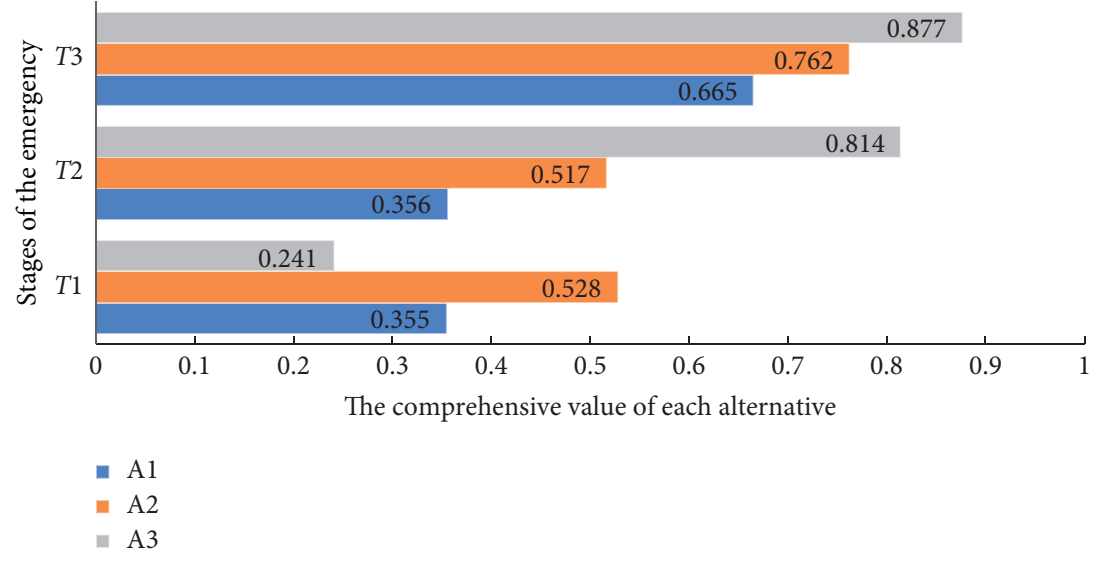

Figure 4: Comprehensive value of each alternative at each stage.

TABLE 7: Results of the comprehensive risk expected score function $\operatorname{RES}\left(x_{i}\right)$.

\begin{tabular}{lll}
\hline$T^{p}$ & $A_{i}$ & $\operatorname{RES}\left(V_{i}^{p}\right)$ \\
\hline & $A_{1}$ & $\operatorname{RES}\left(V_{1}^{1}\right)=-0.119 \eta+0.415$ \\
$T^{1}$ & $A_{2}$ & $\operatorname{RES}\left(V_{2}^{1}\right)=-0.142 \eta+0.599$ \\
& $A_{3}$ & $\operatorname{RES}\left(V_{3}^{1}\right)=-0.094 \eta+0.288$ \\
\hline & $A_{1}$ & $\operatorname{RES}\left(V_{1}^{2}\right)=-0.117 \eta+0.415$ \\
$T^{2}$ & $A_{2}$ & $\operatorname{RES}\left(V_{2}^{2}\right)=-0.141 \eta+0.587$ \\
& $A_{3}$ & $\operatorname{RES}\left(V_{3}^{2}\right)=-0.188 \eta+0.908$ \\
\hline & $A_{1}$ & $\operatorname{RES}\left(V_{1}^{3}\right)=-0.198 \eta+0.764$ \\
$T^{3}$ & $A_{2}$ & $\operatorname{RES}\left(V_{2}^{3}\right)=-0.190 \eta+0.857$ \\
& $A_{3}$ & $\operatorname{RES}\left(V_{3}^{3}\right)=-0.182 \eta+0.968$ \\
\hline
\end{tabular}

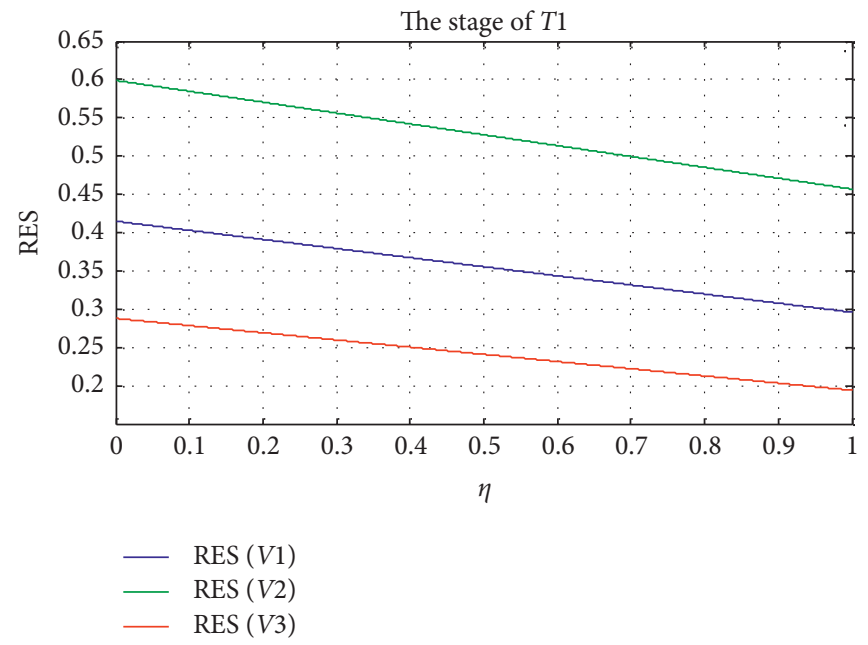

Figure 5: RES $\left(x_{i}\right)$ of stage $T^{1}$.

and psychological pressure. Therefore, under these decisionmaking characteristics, the proposed solution can be applied to enhance the flexibility of decision-making results. (b) Considering the evolution of the emergency, we present a dynamic programming model based on the psychological reference satisfactory degree, to effectively generate and adjust the alternative of each stage. It is better for the dynamic emergency response and not only considers both the dynamic nature of the events and DMs' heterogeneous preference but also generates the optimal adjustment alternation of each evolution stage. (c) With the DMs' risk preference behavior, we introduced the comprehensive risk expected score function to indicate the influence of the DMs' risk attitude and quantify the effect of the risk preference behavior. It can enhance the reliability of decision-making results. 

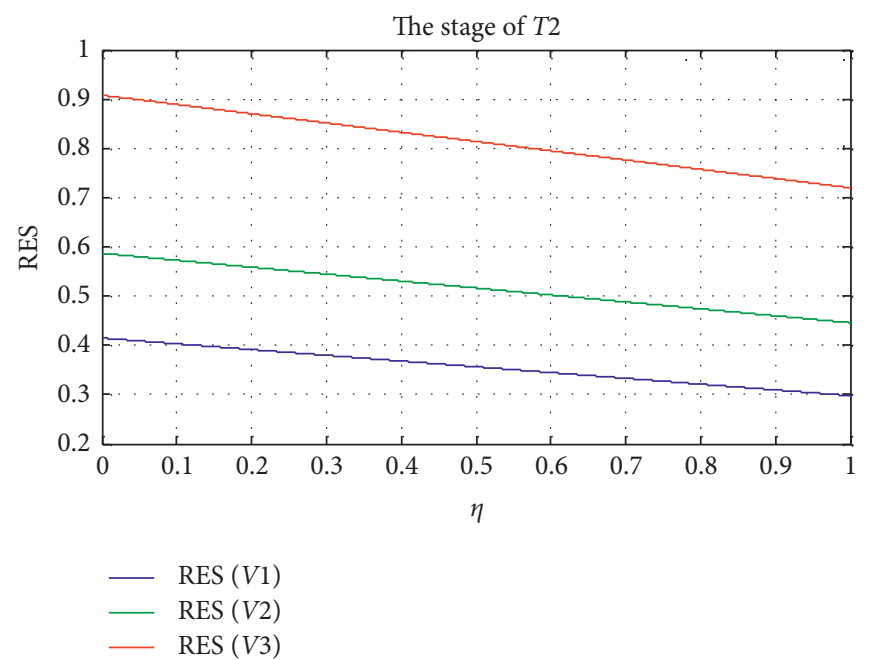

FIgURE 6: RES $\left(x_{i}\right)$ of stage $T^{2}$.

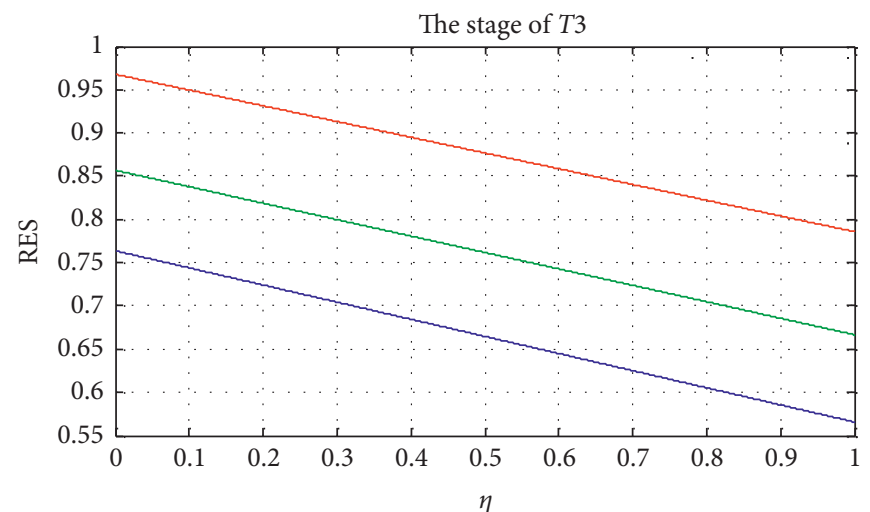

$\begin{array}{ll}- & \operatorname{RES}(V 1) \\ -\quad \operatorname{RES}(V 2) \\ -\quad \operatorname{RES}(V 3)\end{array}$

FIgURE 7: RES $\left(x_{i}\right)$ of stage $T^{3}$.

\section{Concluding Remarks}

Considering the emergency characteristic of the multistage, uncertainty, dynamic, and information updating in reality, we propose a novel MSDEDM approach with interval-valued trapezoidal intuitionistic fuzzy operational laws, psychological reference satisfaction theory, and dynamic programming model. With the emergency developing and decision information updating, we extend the single-stage emergency decision model to the multistage dynamic emergency decision model. Firstly, interval-valued trapezoidal intuitionistic fuzzy theory and method are applied to construct the decisionmaking framework under uncertainty environment. Then, a dynamic programming model is obtained based on the psychological reference satisfactory degree to effectively generate and adjust the alternative of each stage. Based on the programming model, the dynamic updating and adjusting mechanism of the emergency response are proposed. Besides, a sensitivity analysis based on the DMs' risk preference behaviors is conducted to reveal the reliability and effectiveness of the proposed MSDEDM approach. Finally, a practical MSDEDM example of highway emergency is given to illustrate the effectiveness and practicability of the proposed dynamic fuzzy approach. Remarkably, the application implies that the fuzzy theory can well handle the uncertainty of real world in practice and have wide application prospect in other related fields, such as public transport [36-38], logistics network [39-41], and traffic management [42]. The method of the dynamic decision-making procedure would be a useful reference to the similar decision-making researches.

In the future, the proposed MSDEDM method can be applied to the hybrid depiction of the heterogeneous preference assessment information. DMs' new heterogeneous preference behaviors could be also involved, such as loss aversion, anchoring, disappointment, regret theory, and prospect theory. Moreover, the current emerging technology, including big data, data mining, and deep learning, provides a good direction for the development of EDM methods [43]. We strongly suggest integrating the mentioned technology with EDM to provide better measures. 


\section{Data Availability}

The data used to support the findings of this study are available from the corresponding author upon request.

\section{Conflicts of Interest}

The author declares that there are no conflicts of interest regarding the publication of this paper.

\section{Acknowledgments}

This work was supported by the Social Science Foundation of Chongqing of China (nos. 2020BS62 and 2020TBWTZD02), the Special Project of Technology Foresight and System Innovation of Chongqing of China (no. cstc2020jsyjzdxwtB0003), the Research Start-up Funding of Chongqing Jiaotong University (no. 21JDKJC-A021), and the Team Building Project for Graduate Tutors in Chongqing (no. JDDSTD2019008).

\section{References}

[1] L. Zhou, X. Wu, Z. Xu, and H. Fujita, "Emergency decision making for natural disasters: an overview," International Journal of Disaster Risk Reduction, vol. 27, pp. 567-576, 2018.

[2] A. Hafezalkotob, A. Hafezalkotob, H. Liao, and F. Herrera, "An overview of MULTIMOORA for multi-criteria decisionmaking: theory, developments, applications, and challenges," Information Fusion, vol. 51, pp. 145-177, 2019.

[3] Q. Ding, Y. Wang, and M. Goh, "TODIM dynamic emergency decision-making method based on hybrid weighted distance under probabilistic hesitant fuzzy information," International Journal of Fuzzy Systems, 2021.

[4] J. Zheng, Y. Wang, K. Zhang, and J. Liang, "A dynamic emergency decision-making method based on group decision making with uncertainty information," International Journal of Disaster Risk Science, vol. 11, no. 5, pp. 667-679, 2020.

[5] L. Yu and K. Lai, "A distance-based group decision-making methodology for multi-person multi-criteria emergency decision support," Decision Support Systems, vol. 51, no. 2, pp. 307-315, 2011.

[6] Y. Liu, Z. Fan, and Y. Zhang, "Risk decision analysis in emergency response: a method based on cumulative prospect theory," Computers \& Operations Research, vol. 42, no. 2, pp. 75-82, 2014.

[7] L. Wang, Y. Wang, and L. Martínez, "A group decision method based on prospect theory for emergency situations," Information Sciences, vol. 418-419, pp. 119-135, 2017.

[8] Y. Wang, Y. Liang, and H. Sun, "A regret theory-based decision-making method for urban rail transit in emergency response of rainstorm disaster," Journal of Advanced Transportation, vol. 2020, Article ID 3235429, 12 pages, 2020.

[9] X. Xu, Q. Zhang, and X. Chen, "Consensus-based non-cooperative behaviors management in large-group emergency decision-making considering experts' trust relations and preference risks," Knowledge-Based Systems, vol. 190, p. 10, 2020.

[10] P. Ren, Z. Xu, and Z. Hao, "Hesitant fuzzy thermodynamic method for emergency decision making based on prospect theory," IEEE Transactions on Cybernetics, vol. 47, no. 9, pp. 2531-2543, 2017.
[11] Z. Zhang, L. Wang, and Y. Wang, "An emergency decision making method based on prospect theory for different emergency situations," International Journal of Disaster Risk Science, vol. 9, no. 3, pp. 407-420, 2018.

[12] Z. Zhang, L. Wang, and Y. Wang, "An emergency decision making method for different situation response based on game theory and prospect theory," Symmetry, vol. 10, no. 10, p. 476, 2018.

[13] X. Xu, X. Yin, and X. Chen, "A large-group emergency risk decision method based on data mining of public attribute preferences," Knowledge-Based Systems, vol. 163, pp. 495-509, 2019.

[14] Z. Yan, H. Zhao, F. Wang et al., "Rapid assessment of building collapse based on sequential dynamic fusion of multi-source disaster information from news media," International Journal of Disaster Risk Reduction, vol. 51, 2020.

[15] J. Gao, Z. Xu, Z. Liang, and H. Liao, "Expected consistencybased emergency decision making with incomplete probabilistic linguistic preference relations," Knowledge-Based Systems, vol. 176, pp. 15-28, 2019.

[16] X. Li, H. Liao, and Z. Wen, "A consensus model to manage the non-cooperative behaviors of individuals in uncertain group decision making problems during the COVID-19 outbreak," Applied Soft Computing, vol. 99, 2021.

[17] Z. Wang, H. Nie, and H. Zhao, "An extended GEDM method with heterogeneous reference points of decision makers and a new hesitant fuzzy distance formula," Computers \& Industrial Engineering, vol. 146, 2020.

[18] B. Farhadinia and Z. Xu, "An extended hesitant group decision-making technique based on the prospect theory for emergency situations," Iranian Journal of Fuzzy Systems, vol. 17, no. 3, pp. 51-68, 2020.

[19] G. Wei, "Some induced geometric aggregation operators with intuitionistic fuzzy information and their application to group decision making," Applied Soft Computing, vol. 10, no. 2, pp. 423-431, 2010.

[20] Y. Liu, Y. Wang, M. Xu, and G. Xu, "Emergency alternative evaluation using extended trapezoidal intuitionistic fuzzy thermodynamic approach with prospect theory," International Journal of Fuzzy Systems, vol. 21, no. 6, pp. 1801-1817, 2019.

[21] J. Wu and Y. Liu, "An approach for multiple attribute group decision making problems with interval-valued intuitionistic trapezoidal fuzzy numbers," Computers \& Industrial Engineering, vol. 66, no. 2, pp. 311-324, 2013.

[22] G. Wei, "Approaches to interval intuitionistic trapezoidal fuzzy multiple attribute decision making with incomplete weight information," International Journal of Fuzzy Systems, vol. 17, no. 3, pp. 484-489, 2015.

[23] A. Liu, Y. Xiao, H. Lu et al., "A fuzzy three-stage multi-attribute decision-making approach based on customer needs for sustainable supplier selection," Journal of Cleaner Production, vol. 239, pp. 1-16, 2019.

[24] V. L. G. Nayagam, S. Jeevaraj, and P. Dhanasekaran, "An improved ranking method for comparing trapezoidal intuitionistic fuzzy numbers and its applications to multicriteria decision making," Neural Computing and Applications, vol. 30, no. 2, pp. 671-682, 2018.

[25] S. Wan, J. Xu, and J. Dong, “Aggregating decision information into interval-valued intuitionistic fuzzy numbers for heterogeneous multi-attribute group decision making," Knowledge-Based Systems, vol. 113, pp. 155-170, 2016.

[26] X. Ding, H. Liu, and H. Shi, "A dynamic approach for emergency decision making based on prospect theory with 
interval-valued Pythagorean fuzzy linguistic variables," Computers \& Industrial Engineering, vol. 131, pp. 57-65, 2019.

[27] C. Cai, X. Xu, P. Wang, and X. Chen, "A multi-stage conflict style large group emergency decision-making method," Soft Computing, vol. 21, no. 19, pp. 5765-5778, 2017.

[28] J. Wu, X. Liu, Z. Wang, and S. Zhang, "Dynamic emergency decision-making method with probabilistic hesitant fuzzy information based on GM $(1,1)$ and TOPSIS," IEEE Access, vol. 7, pp. 7054-7066, 2019.

[29] X. Xu, B. Pan, and Y. Yang, "Large-group risk dynamic emergency decision method based on the dual influence of preference transfer and risk preference," Soft Computing, vol. 22, no. 22, pp. 7479-7490, 2018.

[30] Z. Hao, Z. Xu, H. Zhao, and H. Fujita, "A dynamic weight determination approach based on the intuitionistic fuzzy bayesian network and its application to emergency decision making," IEEE Transactions on Fuzzy Systems, vol. 26, no. 4, pp. 1893-1907, 2018.

[31] Z. Xu, "Intuitionistic fuzzy multiattribute decision making: an interactive method," IEEE Transactions on Fuzzy Systems, vol. 20, no. 3, pp. 514-525, 2012.

[32] J. Gao, Z. Xu, and H. Liao, "A dynamic reference point method for emergency response under hesitant probabilistic fuzzy environment," International Journal of Fuzzy Systems, vol. 19, no. 5, pp. 1261-1278, 2017.

[33] L. Wang, Z. Zhang, and Y. Wang, "A prospect theory-based interval dynamic reference point method for emergency decision making," Expert Systems with Applications, vol. 42, no. 23, pp. 9379-9388, 2015.

[34] Q. Ding and Y. Wang, "An improved aggregation operatorsbased method for multiple attribute group decision making using interval-valued trapezoidal intuitionistic fuzzy sets," Journal of Intelligent \& Fuzzy Systems, vol. 37, no. 1, pp. 965-980, 2019.

[35] J. Wang and Z. Zhang, "Aggregation operators on intuitionistic trapezoidal fuzzy number and its application to multi-criteria decision making problems," Journal of Systems Engineering and Electronics, vol. 20, no. 2, pp. 321-326, 2009.

[36] J. Tang, Y. Yang, W. Hao et al., "A data-driven timetable optimization of urban bus line based on multi-objective genetic algorithm," IEEE Transactions on Intelligent Transportation Systems, vol. 22, no. 4, pp. 2417-2429, 2020.

[37] J. Tang, Y. Yang, and Y. Qi, "A hybrid algorithm for Urban transit schedule optimization," Physica A: Statistical Mechanics and Its Applications, vol. 512, pp. 745-755, 2018.

[38] W. Wang, D. Wang, H. Sun, and J. Wu, "Public transit service operation strategy under indifference thresholds-based bimodal equilibrium," Journal of Advanced Transportation, vol. 50, no. 6, pp. 1124-1138, 2016.

[39] Y. Wang, X. Ma, Z. Li, Y. Liu, M. Xu, and Y. Wang, "Profit distribution in collaborative multiple centers vehicle routing problem," Journal of Cleaner Production, vol. 144, pp. 203219, 2017.

[40] Y. Wang, S. Peng, X. Zhou, M. Mahmoudi, and L. Zhen, "Green logistics location-routing problem with eco-packages," Transportation Research Part E: Logistics and Transportation Review, vol. 143, p. 102118, 2020.

[41] Y. Wang, Y. Yuan, X. Guan et al., "Collaborative two-echelon multicenter vehicle routing optimization based on statespace-time network representation," Journal of Cleaner Production, vol. 258, p. 120590, 2020.

[42] Y. Zou, B. Lin, X. Yang et al., "Application of the bayesian model averaging in analyzing freeway traffic incident clearance time for emergency management," Journal of Advanced Transportation, vol. 2021, Article ID 6671983, 9 pages, 2021.

[43] M. Tang and H. Liao, "From conventional group decision making to large-scale group decision making: what are the challenges and how to meet them in big data era? A state-ofthe-art survey," Omega, vol. 100, p. 102141, 2021. 